\title{
Treatment-resistant mood disorders
}

\section{Transtornos de humor refratários a tratamento}

\author{
Rodrigo Machado-Vieira, ${ }^{1}$ Jair C Soares ${ }^{2}$
}

\begin{abstract}
Objective and Method: Mood disorders are the most prevalent psychiatric disorders. Despite new insights and advances on the neurobiological basis and therapeutic approaches for bipolar disorders and recurrent depression, elevated prevalence of recurrence, persistent sub-syndromal symptoms and treatment resistance are challenging aspects and need to be urgently addressed. The objective of this literature review is to evaluate the current concepts of treatment resistance and refractoriness in mood disorders. Results: Genetic factors, misdiagnosis, use of inappropriate pharmacological approaches, non-compliance and biological/psychosocial stressors account for dysfunctions in mood regulation, thus increasing the prevalence of refractory mood disorders. Regarding available treatments, the use of effective doses during an adequate period followed by augmentation with a second and/or third agent, and finally switching to other agent are steps frequently necessary to optimize efficacy. However, in the treatment-resistant paradigm, drugs mimicking standard strategies, which target preferentially the monoaminergic system, can present reduced therapeutic effects. Thus, the search for new effective treatments for mood disorders is critical to decreasing the overall morbidity secondary to treatment resistance. Conclusion: Emerging strategies targeting brain plasticity pathways or 'plasticity enhancers', including antiglutamatergic drugs, glucocorticoid receptor antagonists and neuropeptides, have been considered promising therapeutic options for difficult-to-treat mood disorders.
\end{abstract}

Descriptors: Depressive disorder, major; Bipolar disorder; Mood disorders; Antidepressive agents; Refractory period, psychological

\section{Resumo}

Objetivos e Método: Os transtornos de humor estão entre os transtornos psiquiátricos mais prevalentes. Apesar de novas descobertas e avanços no estudo das bases neurobiológicas e abordagens terapêuticas no transtorno bipolar e depressão recorrente, elevadas taxas de recorrência, sintomas subsindrômicos persistentes e refratariedade terapêutica são aspectos clínicos desafiadores e precisam ser abordados. O objetivo desta revisão da literatura é avaliar os conceitos e critérios de resistência e refratariedade ao tratamento, e evidenciar as principais alternativas terapêuticas para transtornos do humor resistentes aos tratamentos disponíveis. Resultados: Fatores genéticos, erro diagnóstico e de tratamento, não-aderência, e estressores biológicos e psicossociais podem levar à perda de mecanismos regulatórios e a aumento na prevalência de casos de refratariedade nos transtornos de humor. Com relação aos tratamentos disponíveis, o uso de doses apropriadas, seguido por associação com um segundo ou terceiro fármaco, e após, se indicado, a troca de medicação, são etapas necessárias na busca de melhor eficácia. Entretanto, no paradigma de refratariedade terapêutica, tratamentos atuando em sistemas já conhecidos, especialmente monoaminas, frequentemente apresentam limitada eficácia. Assim, a busca por tratamentos mais eficazes para os transtornos de humor torna-se um aspecto chave para diminuir sua morbidade. Conclusão: Estratégias focadas na regulação de vias ativadoras de neuroplasticidade, incluindo agentes antig/utamatérgicos, antagonistas de receptor glucocorticóide e neuropeptídeos, podem representar opções terapêuticas promissoras.

Descritores: Transtorno depressivo maior; Transtorno bipolar; Transtornos do humor; Antidepressivos; Período refratário psicológico

\footnotetext{
1 Mood and Anxiety Disorders Program, National Institute of Mental Health, National Institutes of Health, Bethesda, MD, USA

2 Department of Psychiatry, University of North Carolina, Chapel Hill, NC, USA
}

Financing: None

Conflict of interests: None

\section{Correspondence}

Rodrigo Machado-Vieira

35 Convent Drive, Bldg 35, Rm 1C-1010

20892-3711 Bethesda, MD, USA

E-mail: machadovieirar@terra.com.br 


\section{Introduction}

Mood disorders are the most prevalent psychiatric disorders. Bipolar disorder (BD) is a chronic and severe medical illness, affecting about $1.3 \%$ of the population. ${ }^{1}$ Also presenting high morbidity, Unipolar depression (UD) is considered a multifaceted illness regarding its phenomenological structure, which includes somatic, cognitive and behavioral changes ranging from states of increased anxiety and psychomotor activity (e.g. anxious depression) to decreased arousal observed during severe melancholic depression. ${ }^{2}$ The course of mood disorders is fluctuating, usually displaying a characteristic of longer intervals between initial episodes, with posterior decreased intervals as the illness progresses. Risk factors for the development of mood disorders include genetic vulnerability and pervasive psychosocial stressors, which together can trigger the arousal of full-blown episodes. Interestingly, psychosocial stressors have been shown to trigger initial episodes, without significant influence as precipitating factors in subsequent episodes. ${ }^{3}$ Multiple episodes in mood disorders are prevalent and tend to be associated with both inadequate treatment compliance, low psychosocial support, early age of onset and presence of sub-syndromal symptoms. In the major naturalistic study following the course of BD (146 Bipolar I subjects followed for 13 years), it was observed that patients presented symptoms during $47 \%$ of the weeks, which was similar to the rates also observed in Bipolar II (BII) patients (54\% of the weeks), mostly a significant presence of sub-syndromal depressive symptoms compared to manic/hypomanic symptoms in both diagnoses. Polarity shifts presented an average of 3.5 times per/year in Bipolar I and 1.3 in Bll. ${ }^{4}$ Despite the uncontrolled design, these data suggest that subsyndromal symptoms and polarity swings are more common than previously thought and may account for the high morbidity and poor outcomes observed. This review article attempts to provide an overview on future promising approaches for the treatment of treatment-resistant mood disorders.

\section{Non-compliance, response and remission in treatment-resistant mood disorders}

Despite consistent advances in the pharmacotherapy of mood disorders in the last decade, high rates of treatment-resistant mood disorders are still a challenging aspect. The combined use of different agents is often the therapeutic strategy for "difficult to treat" cases. Recovery from manic or depressive episodes is quite important, and adherence to long-term pharmacological treatment is critical to achieving full recovery. Also, it is critical to provide a clear differentiation between episodes secondary to noncompliance and true treatmentresistance. Treatment-resistance has often been defined as a lack of response to three different pharmacological treatments, using continuously therapeutic doses during a sufficient period. ${ }^{5}$ Treatment noncompliance can be better characterized as a risk factor for the development of pharmacological refractoriness. In parallel, response without remission should not be considered as a treatment-resistant condition, but failure to achieve long-term remission (presence of subsyndromal symptoms) has been clearly associated with both increased risk of relapse $e^{6,7}$ and significant deficits in domains related to quality of life/long-term prognosis..$^{8,9}$ For instance, it was demonstrated that not all patients presenting UD benefit from SSRI treatment, with partial or lack of response in $29-46 \%$ of all cases. ${ }^{10}$ Recent data from a multicenter study showed that only $28 \%$ of patients treated with antidepressants obtained remission within 10-14 weeks, whereas after 24 weeks, 50\% presented remission by using a different antidepressant or adjunctive therapy. ${ }^{11}$ Significantly, it has been demonstrated that only half of individuals who responded to an antidepressant achieved complete remission. ${ }^{12}$ These findings suggest that full therapeutic effects may take more than 6 months and despite long-term treatment, a considerable number of patients do not present satisfactory improvement. Thus, it is reasonable to suggest that subsyndromal symptoms due to incomplete remission may strongly account for the chronic course and high long-term morbidity observed in mood disorders.

\section{"Difficult to treat" mood disorders}

An effective agent for the treatment of mood disorders should present effectiveness in a substantial range of symptoms and clinical presentations, as well as displaying few adverse effects and inducing rapid and sustained therapeutic effects. ${ }^{13}$ Considering BD as a complex illness presenting different phases, some agents may be effective only for one phase of the illness. Therefore, polypharmacy is particularly frequent and has been increasingly used for treating persistent subsyndromal symptoms after monotherapy failure. Lithium, valproate and atypical antipsychotics have been considered the first line of treatment for acute mania and maintenance treatment for BD.

Similarly, the therapeutics of Bipolar Depression is a challenging and critical topic and has been also associated with high rates of treatment-resistant cases. The use of antidepressants in Bipolar Depression is not clearly established. The combination of antidepressant and mood stabilizers is widely utilized, but the proper dose and duration of treatment for different agents have not been clearly defined. Although showing considerable efficacy in Bipolar Depression, antidepressants can trigger polarity switch and mood swings, thus increasing the risk of rapid cycling and refractory mood disorders. In general, it has been proposed that antidepressants, lamotrigine or topiramate (combined with a mood stabilizer) comprise first-line treatments for bipolar I depression. For instance, in a large $(n=191)$ double-blind, placebo-controlled study, lamotrigine demonstrated superior antidepressant efficacy compared to placebo after 7 days. ${ }^{14}$ Topiramate has also presented antidepressant efficacy in treatment-resistant bipolardepression, rapid-cycling, acute mania and mixed episodes. ${ }^{15}$ Also, the use of a combination strategy with antidepressants and an atypical antipsychotic has been advocated, but there is a lack of convincing data demonstrating that the combination is more efficacious than the use of an antidepressant alone.

Many approaches have been proposed for treatment-resistant BD. Surprisingly, only psychotherapies have been specifically validated by large-scale controlled trials as add-on treatment to pharmacological agents. Over the last decade, specific psychotherapeutic approaches have been studied, including group psychoeducation, family-focused treatment (FFT), cognitive therapy (CT) and interpersonal and social rhythm therapy (IPSRT). In common, these approaches are tested in order to validate the effectiveness of approaches under a specific structure and proposed target outcomes, including decrease in number of episodes and subsyndromal symptoms, enhanced treatment compliance and improved social functioning. ${ }^{16}$ In acute mania, randomized, double-blind, placebo- controlled studies have shown that olanzapine and risperidone in combination with lithium or valproate induced superior improvement compared to a mood stabilizer alone. Overall, 
Table 1 - Emerging options for treatment-resistant mood disorders

\begin{tabular}{l}
\hline Bipolar disorders \\
\hline New anticonvulsants \\
- Lamotrigine \\
- Topiramate \\
Novel antipsychotics \\
- Olanzapine \\
- Risperidone \\
- Clozapine, Aripiprazole \\
- Quetiapine, Ziprasidone \\
High dose thyroid augmentation \\
Mood stabilizers association \\
ECT \\
Psychosocial adjunctive therapy \\
Allopurinol \\
\hline Major depression \\
\hline Antidepressant combination \\
Atypical antipsychotics \\
Anticonvulsants \\
- Topiramate \\
- Lamotrigine \\
Lithium \\
Somatic treatments (ECT, TMS, VNS, DBS) \\
Anti-glucocorticoids \\
Anti-glutamatergic agents \\
AMPA potentiators \\
Neuropeptides \\
\hline
\end{tabular}

ECT: electroconvulsive therapy; TMS: transcranial magnetic stimulation; VNS: vagus nerve stimulation DBS: deep brain stimulation; AMPA: alpha-amino-35-methyl-4-isoxazolepropionate

olanzapine, risperidone and clozapine have demonstrated both acute antimanic and mood stabilizing effects, with stronger evidence for olanzapine and also considering the limited use of clozapine due to its potential risk for inducing agranulocytosis (Table 1).

Importantly, early establishment of a correct axis I diagnosis is also critical in preventing long-term deleterious effects. A delay in starting proper treatment for mood episodes as well as the use of inappropriate approaches after establishing an incorrect diagnosis (e.g. the use of antidepressant monotherapy for mixed states) may also account for a poor outcome. Similarly, early identification of relevant axis I comorbidities is critical when evaluating "difficult to treat" cases $^{17}$ (Table 2). Substance abuse impacts negatively on short- and long-term outcome, by modifying both treatment response and adherence. ${ }^{18}$ O'Connell et al. observed that patients presenting higher number of prior episodes before initiating lithium treatment were at higher risk for treatmentresistance. ${ }^{19}$ Interestingly, BD subjects presenting initial mania followed by a depressive episode seemed to respond better to lithium compared to rapid cyclers and those presenting initial depressive episodes, which has been associated with a relatively higher rate of treatment-resistance. ${ }^{20}$ Also, discontinuation of lithium treatment has shown to predict a poorer outcome and a subsequent worse response, even when lithium is reintroduced. ${ }^{20}$ The switch rate to mania was $25 \%$ in bipolar patients on placebo or lithium plus an antidepressant, compared with 50\% observed in those treated with tricyclic antidepressants. Taken together, it is observed that incorrect diagnosis and therapeutic approaches, in special those involving the use of antidepressants, put off early initiation of correct treatment and may worsen the short and long-term outcome of BD by shortening cycle lengths and increasing treatment-resistance. In the next sections, we aim to provide an overview of emerging therapeutic strategies for the treatment of refractory mood disorders (Table 1 ).
Key regulators of neuronal plasticity: possible role for emerging new effective therapeutics in mood disorders

Neural plasticity is characterized as the brain's ability to produce adaptive responses by generating of new neural connections secondary to internal and external stimuli or injury. Recent findings have reconceptualized the pathophysiological basis of mood disorders. In this new paradigm, it is proposed that certain experiences, learning and genetic basis can physically change brain structure and affect behavior. A direct involvement of dysfunctions on synaptic plasticity and cellular resilience pathways in the pathophysiology of mood disorders has been suggested. ${ }^{21}$ The relevance of studying neuroplasticity in mood disorders is based on the fact that this integrative process is critically involved in the major risk factors for mood disorders: genetic vulnerability and psychosocial stressors. Altered neurotrophins levels have been widely reported, as well as opposite rescue effects on its levels after pharmacological treatment and clinical improvement. In fact, long-lasting structural and functional changes on brain through alterations in genomic expression involve diverse neural substrates and systems, which in the last decade have been proposed to be related to the course, outcome and therapeutics of mood disorders. Diverse mood stabilizers and antidepressants have been shown to improve neural plasticity and synaptic connectivity by acting in key modulatory circuits related to cell survival and stress regulation. ${ }^{22}$ Promising biochemical and molecular targets for mood stabilizers and antidepressants involve regulatory proteins of neurotrophic cascades such as Bcl-2, CREB/ BDNF, GSK3B and ERK/MAP. For instance, lithium, valproate and diverse antidepressants appear to increase gray matter and activate several neurotrophic signaling cascades, which in turn, directly regulate neurobiological and cognitive processes, such as dendritic/synaptic formation, neurogenesis, learning and memory. ${ }^{23,24}$

Clinical and preclinical studies have demonstrated the possible involvement of BDNF and its receptor trkB (tyrosine kynase B) in antidepressant-like and mood-stabilizing

Table 2 - Integrative biological, clinical and environmental factors involved in the pathophysiology of treatment-resistant mood disorders

\begin{tabular}{l}
\hline Biological variables \\
\hline Family history of mood disorders \\
Early onset \\
Long-term impairment of cellular resilience \\
Pharmacogenetics and pharmacogenomics \\
\\
\hline Clinical and psychosocial aspects \\
\hline Psychosocial stressors \\
Noncompliance \\
Cognitive impairment (primary and secondary) \\
Untreated psychiatric or clinical comorbidities \\
Presence of mood incongruent psychotic symptoms \\
Misdiagnosis \\
Inappropriate therapeutic approach \\
(e.g., use of antidepressant in bipolar disorder) \\
Rapid cycling, mixed episodes
\end{tabular}


effects. ${ }^{24}$ Heterozygous BDNF null mice presented insensitive to antidepressants and hyperactivity, aggressiveness and enhanced startle response, suggesting that BDNF release and trkB signaling are necessary to induce antidepressant-like effects. ${ }^{25}$ Correspondingly, different antidepressant agents have been shown to increase the expression and release of BDNF in hippocampus, ${ }^{26}$ as well as increased prefrontal cortex BDNF expression has been observed in patients taking antidepressants compared to unmedicated subjects. ${ }^{27}$ In BD, BDNF levels has been shown to decrease in mania, also presenting a significant positive correlation with severity of episode. ${ }^{21}$ Also, BDNF activates three important signaling cascades related to induction of neurotrophic effects: the ERK/MAP kinase, PI-3kinase/Akt, and phospholipase $\mathrm{C}$, which have been associated with the neurobiology of BD. ${ }^{24}$ Chronic treatment with lithium and valproic acid showed to up-regulate ERK phosphorylation pathway and genetic manipulations on BDNF -ERK kinase pathways have been shown to generate diverse behavioral changes associated with mood regulation. ${ }^{28}$ Similarly, CAMPCREB, the final pathway for ERK, plays a direct role in neuroplasticity, cell survival, and behavioral regulation by modulating hormones, growth factors and synaptic plasticity pathways, which showed to be decreased in UD and upregulated after chronic antidepressant treatment. ${ }^{29}$ CREB also induces a direct regulatory effect related to the BDNF-induced antidepressant effects. CREB stimulates BDNF production, which in turn, induces CREB phosphorylation. ${ }^{30}$ Currently, CREB itself is still not a suitable target for pharmacotherapy and there are no direct CREB agonists or antagonists available. In the future, direct CREB-regulated molecules might represent potential targets for the development of new effective therapeutics in mood disorders.

Similarly, recent data have also demonstrated positive regulatory effects on cellular signaling neurotrophic induced by the neuroprotective protein $\mathrm{Bcl}-2$, which was shown to be a relevant target on mood regulation. $\mathrm{Bcl}-2$ has been intrinsically associated with mitochondrial activity, calcium levels and oxidative stress parameters, which have been shown to be involved in the pathophysiology of BD. Moreover, lithium and valproate consistently increased Bcl-2 mRNA levels, whereas chronic stress, a major risk factor for mood disorders, presented opposite effects on its expression. Also, inactivation of the proapoptotic protein GSK-3B induced antimanic and antidepressant effects in animal models. ${ }^{31}$ Interestingly, downregulation of GSK-3B expression has been associated with the molecular effects induced by lithium and antidepressants. ${ }^{30}$ This complex process may be well characterized as a progressive dysfunctional bio-behavioral interaction leading to arousal of mood episodes and potential treatment resistance (see Table 2). Based on these findings, a neuronal dysregulation leading to impaired neuroplasticity and cellular resilience has been proposed to display a critical pathophysiological role in the mood regulation. ${ }^{24}$ In this context, agents targeting on plasticity pathways have been considered emerging therapeutic options for severe and refractory BD and UD, including several classes of potential "plasticity enhancers" such as NMDA antagonists, inhibitors of glutamate-release, AMPA potentiators (AMPAkines), glucocorticoid receptor antagonists and neuropeptides.

Stress and glucocorticoids: potential targets for treatment-resistant BD and depression

Since three decades ago, a hyperactive hypothalamic- pituitary-adrenal (HPA) axis has been associated with the pathophysiology of mood disorders. Depressive syndrome occurs in more than $50 \%$ of patients presenting Cushing's syndrome or under treatment with exogenous corticosteroids. This major "stress pathway" begins in the hypothalamic lateral ventricular nucleus, which, by releasing corticotropin-releasing factor (CRF), stimulates the production of adrenocorticotropin-releasing hormone $(\mathrm{ACTH})$ in the pituitary. Sequentially, ACTH induces the production of glucocorticoids such as cortisol. A hyperactive HPA axis activates the CRF pathway and induces glucocorticoids hypersecretion, potentially leading to injury and atrophy on hippocampal neurons (which express high levels of receptors for glucocorticoids). ${ }^{32,33}$ Interestingly, glucocorticoids were found to decrease the expression of BDNF in the hippocampus, which may possibly explain the inhibitory effects induced by corticosteroids at the neuroplasticity pathways.

Dysfunctions in glucocorticoid receptors (GR) metabolism have been shown to induce an ample range of biological stresses, which can in turn precipitate both depressive and manic symptoms in susceptible subjects. Neurobiological findings have demonstrated that hyperactive HPA axis precipitates the arousal of depressive symptoms, mostly due to elevation in cerebrospinal fluid CRF levels. Taking into account the strong evidence supporting the involvement of dysfunctions in the HPA axis in the "stress-induced" pathophysiological basis of mood disorders, clinical and preclinical studies have investigated the therapeutic effects of drugs exerting regulatory effects on HPA axis, including GR and CRF antagonists. GR antagonists have shown to block the harmful effects of hypercortisolemia, mostly due to blockade at GR receptors. GR antagonists have been demonstrated to induce an acute antiglucocorticoid effect, which may generate a negative feedback in the HPA axis. For instance, mifepristone (RU486), a non-selective antagonist of the GR receptor, has been shown to possess antidepressant and antipsychotic effects in psychotic depression. ${ }^{34}$ In bipolar depression, clinical use of mifepristone (600 mg/day) presented not only improvement in depressive symptoms compared to placebo, but also induced improvement in cognitive functioning. Also, inhibition of glucocorticoid synthesis and release has been considered a potential therapeutic target for the treatment of major depression. Treatment with glucocorticoid synthesis inhibitors (GSIS), such as ketoconazole and metyrapone, has demonstrated to significantly improve depressive symptoms in clinical and pre-clinical studies. In a double-blind, randomized, placebo-controlled trial, metyrapone showed efficacy as adjunctive treatment in major depression, accelerating the onset of antidepressant action. ${ }^{35}$ Ketoconazole also showed to reduce cortisol levels in major depression, but these preliminary results need replication.

The CRF family of neuropeptides and receptors has been shown to significantly modulate systems related to mood regulation, such as emotionality, locomotor activity, sleep-wake cycle and aversive processes. ${ }^{36}$ CRF1 receptor antagonists have demonstrated therapeutic antidepressant-like effects. The pyrrolopyridimine compound antalarmin presented a decrease in the stress-induced CRF-stimulated corticotrophin release. It also demonstrated to block the stress-induced inhibition of exploratory and sexual behaviors. Similarly, the adrenal steroid dehydroepiandrosterone (DHEA) acts as a precursor to the sexual hormones, such as testosterone and estrogen, and 
clinical studies have demonstrated its antidepressant efficacy during major depressive episodes. Clinical use of DHEA (30$90 \mathrm{mg} / \mathrm{day}$ for 4 weeks) has been shown to induce antidepressant effects in dysthymia and depression. ${ }^{37}$ In addition, elevated cortisol/DHEA ratio was correlated to higher scores for anxiety, anger, depression and hostility in treatmentresistant psychotic patients. Thus, available data support the hypothesis that dysfunctional HPA axis is a hallmark of major depression, but the precise mechanism by which glucocorticoids may generate these deleterious effects on the brain is not fully elucidated, but is proposed to involve enhanced glutamatergic signaling and inhibition of glucose transport.

Taken together, recent findings support the notion that GR can play a relevant role in the therapeutic response in mood disorders, potentially associated with regulatory effects targeting at plasticity pathways.

\section{Glutamatergic strategies for treatment-resistant mood disorders}

Glutamatergic metabolism has been implicated in the modulation of synaptic plasticity, learning, and memory and increased glutamate neurotransmission activates a range of signaling cascades associated with mitochondrial energy metabolism. ${ }^{38}$ Interestingly, the presence of both elevated calcium levels and mitochondrial dysfunction has been described in $\mathrm{BD},{ }^{39}$ suggesting indirectly, an additional role for glutamatergic metabolism in the pathophysiology of BD. Consequently, experimental therapeutics for mood disorders have been implemented to reduce glutamate-mediated excitotoxicity, which results in strong neuroprotective effects in an ample range of preclinical paradigms.

NMDA receptors (NMDAr) are the most widespread ionotropic receptors and represent the primary target for glutamatergic agents in the treatment of mood disorders. The original observations date back to the 1960s, based on reports of mood-elevating effects induced by D-cycloserine (an NMDAr partial agonist). AMPA receptors (AMPAr) mediate fast glutamate signaling and critically regulate calcium metabolism, plasticity and oxidative stress. ${ }^{40}$ At the same time, elevated calcium levels and increased oxidative stress take place during this condition. Positive allosteric modulators of AMPA receptors (AMPAkines) were recently shown to have antidepressant-like effects in diverse models, as well as enhanced cognitive activity by increasing hippocampal BDNF expression. ${ }^{41}$ In one study, the AMPAkine Ampalex induced faster antidepressant response (improvement in the first week) compared to fluoxetine. ${ }^{42}$ Recently, positive allosteric modulators of AMPA receptors (AMPAkines) have been developed and are undergoing clinical investigation for diverse psychiatric and neurological disorders, including piracetam, benzothiazides (cyclothiazide), benzylpiperidines (CX-516, CX-546) and biarylpropylsulfonamides (LY392098, LY404187 and LY503430). ${ }^{43}$

Another class of glutamatergic agents, called glutamatergic modulators, has been tested for the treatment of BD and UD, apparently producing therapeutic by increasing AMPA to NMDA throughput. ${ }^{43}$ Riluzole and lamotrigine, have been shown to induce of glutamate release and activation of neurotrophic factors, which has been considered critical to achieve antidepressant effects in treatment-resistant major depression and bipolar depression. ${ }^{25,44}$ Riluzole is a neuroprotective and neurotrophic agent exerting its anti-glutamatergic effects through the inhibition of voltage-dependent sodium channels in neurons and by reducing glutamate, whereas lamotrigine exerts its pharmacological effect mostly due to inhibition of excessive presynaptic release of glutamate. Riluzole showed to significantly improve depressive symptoms as measured by the Montgomery-Asberg Depression Rating Scale (MADRS) on weeks 3 through 6 for all patients. ${ }^{44}$ Also, an 8-week openlabel clinical trial with riluzole in 14 patients presenting bipolar depression showed a significant improvement as an add-on treatment to lithium. ${ }^{25}$ The response and remission rates at week 8 for the intent-to-treat analysis were $50 \%$.

Likewise, NMDAr antagonists appear to have antidepressant effects in refractory depression. In humans, ketamine, a noncompetitive NMDA glutamate receptor antagonist, showed significant efficacy in the treatment of major depression. ${ }^{45}$ Ketamine acts by antagonizing the NMDAr and thus preventing excess $\mathrm{Ca}$ influx and cellular damage. In double-blind, placebo controlled clinical trials with chronically depressed subjects, single doses of ketamine produced fast and sustained antidepressant effects, which persisted for a week following infusion. ${ }^{45}$ Also, ketamine induced significant antidepressant effects in animal models of depression. ${ }^{46}$ Other studies have tested the possible therapeutic role of several NMDA antagonists, including felbamate and zinc. Felbamate (2phenyl-1,3 propanodiol dicarbamate) is an anticonvulsant and neuroprotective agent, which presents stimulant-like effects in patients with epilepsy. Studies have described positive reports with felbamate on mood modulation, based on findings of improved alertness, attention, concentration and social function. ${ }^{47}$ In children taking felbamate, improved attention, alertness and initiative were reported. Also, Zinc is a potent inhibitor of the NMDA receptor, and a growing body of evidence suggests the involvement of zinc metabolism in the pathophysiology of mood disorders, with potential therapeutic effects for depressive episodes. Studies have described low serum zinc levels during depressive episodes and that zinc reduces depressive-like symptoms in diverse animal models of depression. ${ }^{48}$ In addition, similarly to antidepressant drugs, treatment with zinc increased cortical BDNF mRNA levels. These data indicate a critical and complex role for the interaction between zinc and NMDA receptor complex in the mechanism of antidepressant treatment and support the involvement of glutamatergic pathways in the antidepressant action.

\section{Other therapeutic options for treatment-resistant mood disorders}

The clinical use of cytokines and neuropeptides might also represent new potential targets for the development of novel pharmacological treatments for mood disorders. Recently, a receptor-specific nonpeptidergic galanin GAL3 receptor antagonists (SNAP-37889 and SNAP-398299) have shown antidepressant properties, ${ }^{49}$ but still need to be confirmed by controlled clinical studies. Despite lacking replication in additional controlled studies, phenytoin, oxcarbazepine, leviracetam, topiramate and high doses of thyroid augmentation may have therapeutic effects in BD (either mania, bipolar depression or maintenance therapy), and may also represent promising augmentation therapies for refractory $B D$. Other effective options for treatmentresistant cases include MAO inhibitors. ${ }^{50}$ Somatic treatment also may play a role in the therapeutics of treatment-resistant depression, including vagus nerve stimulation (VNS), transcranial magnetic stimulation (TMS), and deep brain stimulation (DBS). 


\section{Final remarks}

Recent findings have led to a reconceptualization of the pathophysiological basis of mood disorders. The hypothesis that abnormalities in neuronal resilience and plasticity may determine the onset of these illnesses has gained momentum. The development of new effective pharmacological treatments for mood disorders may provide a better outcome for many patients by preventing deleterious effects on biological and psychosocial functioning. Strategies focusing on the study of small molecule agents and their regulatory effects on multiple candidate genes for cellular plasticity, such as growth factors, MAPK cascades, and the $\mathrm{Bcl}-2$ family of proteins are promising targets for further studies. Agents capable of reversing mitochondrial-induced impairments on energy metabolism and cellular plasticity, acting as "plasticity enhancers", such as antiglutamatergic and antiglucocorticoid drugs, may also be considered promising targets for the development of new effective therapeutics for these devastating illnesses.

\section{Acknowledgements}

Staff of the Laboratory of Molecular Pathophysiology and Mood Disorders Research Unit, National Institute of Mental Health-NIH, USA, Stanley Medical Research Institute-USA, CAPES, and CNPq.

\section{References}

1. Rush AJ. Toward an understanding of bipolar disorder and its origin J Clin Psychiatry. 2003;64(Suppl 6):18-22; discussion 28.

2. Katz MM, Koslow SH, Frazer A. Onset of antidepressant activity: reexamining the structure of depression and multiple actions of drugs. Depress Anxiety. 1996-1997;4(6):257-67.

3. Post RM. Adjunctive strategies in the treatment of refractory bipolar depression: clinician options in the absence of a systematic database. Expert Opin Pharmacother. 2005;6(4): 531-46.

4. Judd LL, Akiskal HS, Schettler PJ, Endicott J, Maser J, Solomon DA, Leon AC, Rice JA, Keller MB. The long-term natural history of the weekly symptomatic status of bipolar I disorder. Arch Gen Psychiatry. 2002;59(6):530-7.

5. Phillips KA, Nierenberg AA. The assessment and treatment of refractory depression. J Clin Psychiatry. 1994;55(Suppl):20-6.

6. Van Londen L, Molenaar RP, Goekoop JG, Zwinderman AH, Rooijmans HG. Three- to 5-year prospective follow-up of outcome in major depression. Psychol Med. 1998;28(3):731-5.

7. Lewis L, Hoofnagle L. Treatment-resistant depression: the patient perspective. Biol Psychiatry. 2003;53(8):635-9.

8. Gitlin MJ, Swendsen J, Heller TL, Hammen C. Relapse and impairment in bipolar disorder. Am J Psychiatry. 1995;152(11):1635-40.

9. Parker G, Wilhelm K, Mitchell P, Gladstone G. Predictors of 1year outcome in depression. Aust $N$ Z J Psychiatry. 2000;34(1):56-64.

10. Fava M, Vuolo RD, Wright EC, Nierenberg AA, Alpert JE, Rosenbaum $\mathrm{JF}$. Fenfluramine challenge in unipolar depression with and without anger attacks. Psychiatry Res. 2000;94(1):9-18.

11. Trivedi MH, Fava M, Wisniewski SR, Thase ME, Quitkin F, Warden D, Ritz L, Nierenberg AA, Lebowitz BD, Biggs MM, Luther JF, ShoresWilson K, Rush AJ: STAR*D Study Team. Medication augmentation after the failure of SSRIs for depression. N Engl J Med. 2006;354(12): 1243-52.

12. Kupfer DJ, Charney DS. Difficult-to-treat depression. Biol Psychiatry. 2003;53(8):633-4.

13. Machado-Vieira R, Zarate CA, Manji HK. Emerging Novel Treatments for Severe Mood Disorders Involving Cellular Plasticity Cascades. Current Psychosis Ther Rep. 2006;4(4):181-90

14. Calabrese JR, Bowden CL, Sachs GS, Ascher JA, Monaghan E, Rudd GD. A double-blind placebo-controlled study of lamotrigine monotherapy in outpatients with bipolar I depression. Lamictal 602 Study Group. J Clin Psychiatry. 1999;60(2):79-88.
15. Vieta E, Torrent C, Garcia-Ribas G, Gilabert A, Garcia-Pares G, Rodriguez A, Cadevall J, Garcia-Castrillon J, Lusilla P, Arrufat F . Use of topiramate in treatment-resistant bipolar spectrum disorders. J Clin Psychopharmacol. 2002;22(4):431-5.

16. Miklowitz DJ, Richards JA, George EL, Frank E, Suddath RL, Power KB, Sacher JA.. Integrated family and individual therapy for bipolar disorder: results of a treatment development study. J Clin Psychiatry. 2003;64(2): 182-91.

17. Singh JB, Zarate CA Jr. Pharmacological treatment of psychiatric comorbidity in bipolar disorder: a review of controlled trials. Bipolar Disord. 2006;8(6):696-709.

18. Aagaard J, Vestergaard P. Predictors of outcome in prophylactic lithium treatment: a 2-year prospective study. J Affect Disord. 1990;18(4):259-66.

19. O'Connell RA, Mayo JA, Flatow L, Cuthbertson B, O'Brien BE. Outcome of bipolar disorder on long-term treatment with lithium. $\mathrm{Br}$ J Psychiatry. 1991;159:123-9.

20. Post RM, Ketter TA, Pazzaglia PJ, Denicoff K, George MS, Callahan A, Leverich G, Frye M . Rational polypharmacy in the bipolar affective disorders. Epilepsy Res Suppl. 1996;11:153-80.

21. Machado-Vieira R, Dietrich MO, Leke R, Cereser VH, Zanatto V, Kapczinski F, Souza DO, Portela LV, Gentil V. Decreased plasma brain derived neurotrophic factor levels in unmedicated bipolar patients during manic episode. Biol Psychiatry. 2007;61(2):142-4.

22. Manji HK, Moore GJ, Chen G. Clinical and preclinical evidence for the neurotrophic effects of mood stabilizers: implications for the pathophysiology and treatment of manic-depressive illness. Biol Psychiatry. 2000;48(8):740-54.

23. Manji HK, Lenox RH. The nature of bipolar disorder. J Clin Psychiatry. 2000;61(Supp 13):42-57.

24. Manji HK, Duman RS. Impairments of neuroplasticity and cellular resilience in severe mood disorders: implications for the development of novel therapeutics. Psychopharmacol Bull. 2001;35(2):5-49.

25. Zarate CA Jr, Quiroz JA, Singh JB, Denicoff KD, De Jesus G, Luckenbaugh DA, Charney DS, Manji HK. An open-label trial of the glutamate-modulating agent riluzole in combination with lithium for the treatment of bipolar depression. Biol Psychiatry. 2005;57(4):430-2.

26. Chen B, Dowlatshahi D, MacQueen GM, Wang JF, Young LT. Increased hippocampal BDNF immunoreactivity in subjects treated with antidepressant medication. Biol Psychiatry. 2001;50(4):260-5.

27. Karege F, Bondolfi G, Gervasoni N, Schwald M, Aubry JM, Bertschy G. Low brain-derived neurotrophic factor (BDNF) levels in serum of depressed patients probably results from lowered platelet BDNF release unrelated to platelet reactivity. Biol Psychiatry. 2005;57(9): 1068-72.

28. Chen G, Manji HK. The extracellular signal-regulated kinase pathway: an emerging promising target for mood stabilizers. Curr Opin Psychiatry. $2006 ; 19(3): 313-23$.

29. Manji HK, Quiroz JA, Sporn J, Payne JL, Denicoff KA, Gray N, Zarate CA Jr, Charney DS. Enhancing neuronal plasticity and cellular resilience to develop novel, improved therapeutics for difficult-totreat depression. Biol Psychiatry. 2003;53(8):707-42.

30. Gould TD, Manji HK. Glycogen synthase kinase-3: a putative molecular target for lithium mimetic drugs. Neuropsychopharmacology. 2005;30(7):1223-37.

31. Zarate CA, Singh JB, Carlson PJ, Brutsche NE, Ameli R, Luckenbaugh DA, Charney DS, Manji HK. A randomized trial of an N-methyl-Daspartate antagonist in treatment-resistant major depression. Arch Gen Psychiatry. 2006;63(8):856-64.

32. Duman RS, Monteggia LM. A neurotrophic model for stress-related mood disorders. Biol Psychiatry. 2006;59(12):1116-27.

33. Brown JM, Yamamoto BK. Effects of amphetamines on mitochondrial function: role of free radicals and oxidative stress. Pharmacol Ther. 2003;99(1):45-53.

34. Belanoff JK, Rothschild AJ, Cassidy F, DeBattista C, Baulieu EE, Schold C, Schatzberg AF. An open label trial of C-1073 (mifepristone) for psychotic major depression. Biol Psychiatry. 2002;52(5):386-92

35. J ahn H, Schick M, Kiefer F, Kellner M, Yassouridis A, Wiedemann K. Metyrapone as additive treatment in major depression: a doubleblind and placebo-controlled trial. Arch Gen Psychiatry. 2004;61(12):1235-44 
36. Heinrichs SC, Koob GF. Corticotropin-releasing factor in brain: a role in activation, arousal, and affect regulation. J Pharmacol Exp Ther. 2004;311(2):427-40.

37. Wolkowitz OM, Reus VI, Roberts E, Manfredi F, Chan T, Ormiston S, Johnson R, Canick J, Brizendine L, Weingartner H. Antidepressant and cognition-enhancing effects of DHEA in major depression. Ann N Y Acad Sci. 1995;774:337-9.

38. Drevets WC. Neuroimaging and neuropathological studies of depression: implications for the cognitive-emotional features of mood disorders. Curr Opin Neurobiol. 2001;11(2):240-9.

39. Hough C, Lu SJ, Davis CL, Chuang DM, Post RM. Elevated basal and thapsigargin-stimulated intracellular calcium of platelets and lymphocytes from bipolar affective disorder patients measured by a fluorometric microassay. Biol Psychiatry. 1999;46(2):247-55.

40. Zarate CA Jr, Du J, Quiroz J, Gray NA, Denicoff KD, Singh J, Charney DS, Manji HK. Regulation of cellular plasticity cascades in the pathophysiology and treatment of mood disorders: role of the glutamatergic system. Ann N Y Acad Sci. 2003;1003:273-91.

41. Lauterborn JC, Lynch G, Vanderklish P, Arai A, Gall CM. Positive modulation of AMPA receptors increases neurotrophin expression by hippocampal and cortical neurons. J Neurosci. 2000;20(1):8-21.

42. Knapp RJ, Goldenberg R, Shuck C, Cecil A, Watkins J, Miller C, Crites G, Malatynska E. Antidepressant activity of memoryenhancing drugs in the reduction of submissive behavior model. Eur J Pharmacol. $2002 ; 440(1): 27-35$.

43. Du J, Machado-Vieira R, Maeng S, Martinowich K, Manji HK, Zarate CA. Enhancing AMPA to NMDA throughput as a convergent mechanism for antidepressant action. Drug Discov Today. 2007;12(3-4):519-26.

44. Zarate CA Jr, Payne JL, Quiroz J, Sporn J, Denicoff KK, Luckenbaugh D, Charney DS, Manji HK. An open-label trial of riluzole in patients with treatment-resistant major depression. Am J Psychiatry. 2004;161(1):171-4.

45. Zarate CA Jr, Singh JB, Carlson PJ, Brutsche NE, Ameli R, Luckenbaugh DA, Charney DS, Manji HK. A randomized trial of an $\mathrm{N}$-methyl-D-aspartate antagonist in treatment-resistant major depression. Arch Gen Psychiatry. 2006;63(8):856-64.

46. Silvestre JS, Nadal R, Pallares M, Ferre N. Acute effects of ketamine in the holeboard, the elevated-plus maze, and the social interaction test in Wistar rats. Depress Anxiety. 1997;5(1):29-33.

47. Ketter TA, Malow BA, Flamini R, Ko D, White SR, Post RM, Theodore WH. Felbamate monotherapy has stimulant-like effects in patients with epilepsy. Epilepsy Res. 1996;23(2):129-37.

48. Nowak G, Szewczyk B, Pilc A. Zinc and depression. An update. Pharmacol Rep. 2005;57(6):713-8.

49. Ogren SO, Kuteeva E, Hokfelt T, Kehr J. Galanin receptor antagonists: a potential novel pharmacological treatment for mood disorders. CNS Drugs. 2006;20(8):633-54.

50. Fleck MP, Horwath E. Pharmacologic management of difficult-totreat depression in clinical practice. Psychiatr Serv. 2005;56(8): 1005-11. 